\title{
Penyaringan Metode Buchner Sebagai Alternatif Pengganti Penyaringan Sederhana Pada Percobaan Adsorpsi Dalam Pratikum Kimia Fisika
}

\author{
Prastyo $^{1}$ dan Ani Sri Rahayoe ${ }^{2}$ \\ ${ }^{1}$ Laboratorium Kimia Fisika, Departemen Kimia, Fakultas MIPA, \\ Universitas Gadjah Mada, \\ Sekip Utara BLS 21 Yogyakarta 55281 \\ prastyo@ugm.ac.id \\ ${ }^{2}$ Laboratorium Sistematika Hewan, Fakultas Biologi, Universitas Gadjah Mada, \\ Jl. Teknika Selatan, Sinduadi, Mlati, Sleman, Yogyakarta 55281
}

\begin{abstract}
ABSTRAK
Penyaringan merupakan pemisahan fisik antara cairan dan padatan dalam campuran. Selain menggunakan gravitasi untuk memaksa cairan melewati medium septum dapat pula digunakan gaya pendorong dengan vakum. Pada percobaan adsorpsi dalam praktikum kimia fisika masih menggunakan penyaringan sederhana. Metode ini memerlukan waktu lama dan filtrat secara visual belum jernih. Hal tersebut memunculkan ide penggunaan metode Buchner sebagai alternatif untuk mendukung pelaksanaan praktikum yang lebih efisien. Telah diujicobakan metode Buchner dengan vakum pompa dengan power $1 / 4 \mathrm{HP}$, voltage $220 \mathrm{~V} / 50 \mathrm{~Hz}$, Model RS-1 $(B V P)$, metode Buchner dengan vakum air kran (BVAK), dan metode penyaringan sederhana sebagai pembanding. Suspensi yang digunakan adalah 2 gram zeolit dimasukan kedalam erlenmeyer $250 \mathrm{ml}$ berisi larutan $35 \mathrm{ml}$ asam asetat $1 \mathrm{~N}$, penyaringan dengan kertas saring whatman. Hasil proses penyaringan metode BVP memerlukan waktu berkisar 2,33-3 menit (paling cepat) dengan filtrat jernih; proses penyaringan metode BVAK memerlukan waktu antara 3,5-4,25 menit dengan filtrat jernih; dan waktu penyaringan sederhana memerlukan waktu antara 9,5-11 menit dengan filtrat masih keruh. Mempertimbangkan waktu dan filtrat maka metode Buchner dengan vakum pompa (BVP) maupun dengan vakum air kran (BVAK) dapat digunakan sebagai alternatif pengganti metode penyaringan pada percobaan adsorpsi dalam praktikum kimia fisika.
\end{abstract}

Kata kunci: Penyaringan, Buchner, Adsorbsi, kimia fisika

\section{PENDAHULUAN}

Penyaringan

pembersihan atau pemisahan partikel padat dari suatu fluida dengan melewatkannya pada medium penyaringan atau septum yang menahan zat padat. Untuk memaksa cairan melewati septum diperlukan gaya pendorong dalam bentuk: gaya berat (gravity filtration), vakum (vacuum filtration), tekanan (pressure filtration), gaya sentrifugal (centrifugal filtration). Metode yang ada tersebut memiliki kelebihan dan kekurangan masing-masing (Anonim, 2018).

Kegiatan Praktikum Kimia Fisik pada kegiatan percobaan adsorpsi yang biasa dilakukan menggunakan penyaringan sederhana yaitu dengan menggunakan corong kaca diberikan kertas saring yang diletakan pada statif dan dibawahnya diberikan penampung filtrat berupa Erlenmeyer ( Gambar 1). Metode filtrasi dengan gravitasi ini (gravity filtration)memerlukan waktu yang cukup lama untuk menghasilkan filtrat yang 
diperlukan. Proses tersebut menyita waktu untuk aktifitas praktikum berikutnya disamping itu filtrat secara visual masih kurang jernih. Hal ini menjadi dasar untuk mencari alternatif penggunaan metode penyaringan yang lebih baik.

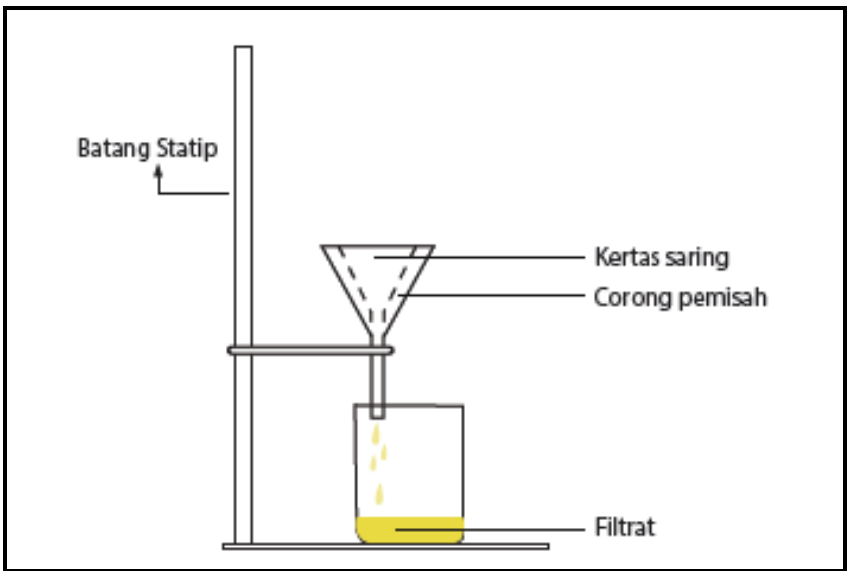

Gambar 1. Penyaringan sederhana dengan corong kaca (Anonim, 2018)

Metode penyaringan Buchner (Gambar 2) dapat mempercepat proses penyaringan. Metode penyaringan Buchner menggunakan corong Buchner kertas saring dan vakum. Fungsi dari vakum dapat mempercepat proses penyaringan dan filtrat hasil metode ini lebih jernih. Kelebihan metode ini dan ketersediaan alat yang ada di laboratorium menjadi pertimbangan untuk digunakan sebagai metode alternatif. Proses vakum digunakan pompa vakum dan vakum air kran.

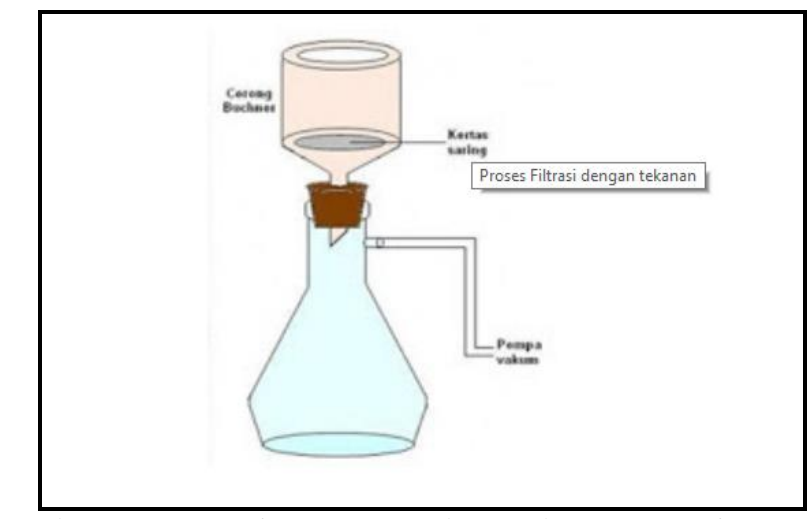

Gambar 2. Penyaringan Metode Buchner (Anonim, 2018)

Tujuan penelitian ini untuk mendapatkan metode alternatif proses penyaringan yang lebih cepat dan mendapatkan Filtrat yang lebih jernih dari

\section{METODE PENELITIAN}

Alat yang digunakan dalam penelitian ini adalah: corong gelas, elenmeyer $250 \mathrm{ml}$, gelas beker $250 \mathrm{ml}, 1$ set proses penyaringan sederhana pada percobaan adsorpsi dalam kegiatan Praktikum Kimia Fisika.

\section{Bahan dan alat}

penyaringan Buchner $250 \mathrm{ml}$, pompa vakum, vakum air kran, pengaduk gelas, pipet tetes, dan stopwatch. 
Bahan yang digunakan adalah kertas saring whatman biasa, zeolit, asam asetat $1 \mathrm{~N}$, air kran. Penelitian ini menggunakan metode Buchner dengan vakum menggunakan pompa vakum (BVP) dan metode Buchner dengan vakum menggunakan air kran (BVAK), dan metode penyaringan sederhana yang biasa digunakan sebagai pembanding.

Peralatan untuk penyaringan metode Buchner dengan vakum pompa (BVP) diatur penyaring Buchner dengan kertas saring watman biasa, diletakkan diatas elenmeyer $250 \mathrm{ml}$ dengan vakum dihubungkan pompa vakum pompa dengan power $1 / 4 \mathrm{HP}$, voltage $220 \mathrm{~V} / 50 \mathrm{~Hz}$, Model RS-1 (BVP). Untuk metode Buchner dengan vakum air kran (BVAK) 1 set penyaringan Buchner, vakum dihubungkan alat vakum air kran. Untuk penyaringan sederhana diatur corong kaca diberi kertas saring yang sudah dilipat sesuai permukaan corong, diletakkan di atas erlenmeyer 250 $\mathrm{ml}$. Peralatan ketiga metode penyaringan dapat dilihat pada Gambar 3.

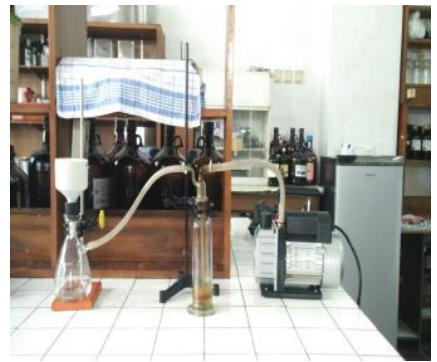

A. BVP

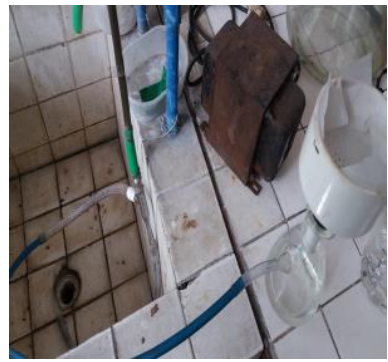

B. BVAK

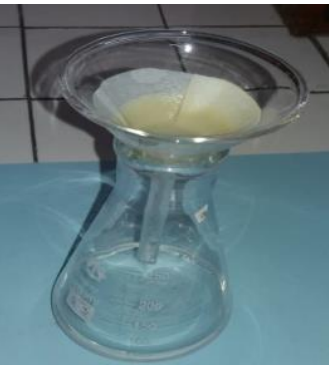

C. Penyaringan Sederhana

Gambar 3. Penataan Alat Penyaringan

Tiga buah erlenmeyer $250 \mathrm{ml}$ yang berisi: @ zeolite 2 gram dan $35 \mathrm{ml}$ asam asetat $1 \mathrm{~N}$, digojok selama 1 menit, kemudian suspensi dilakukkan penyaringan:

a. Metode penyaringan Buchner dengan pompa vakum (BVP)

Hasil pengamatan waktu yang dibutuhkan pada masing-masing proses penyaringan dengan 3 metode yang berbeda dapat dilihat pada Tabel 1. Adapun hasil b. Metode penyiaringan Bucher dengan vakum air kran (BVAK)

c. Penyaringan Sederhana

Demudian diamati waktu penyaringa dan diamati hasil penyaringan (filtrat) secara visual kualitatif.

\section{HASIL DAN PEMBAHASAN}

penyaringan/filtrat dari masing-masing metode ditampilkan pada Tabel 2 dan Gambar 4.

\begin{tabular}{|c|c|c|c|}
\hline \multirow{2}{*}{ No } & \multirow{2}{*}{ Metode Penyaringan } & \multicolumn{2}{|c|}{ Waktu Penyaringan } \\
\hline & & Percobaan I & Percobaan II \\
\hline & BVP & 2’20”' & 3 ' \\
\hline & BVAK & $3^{\prime} 30^{\prime \prime}$ & 4'15" \\
\hline & Penyaringan Sederhana & 9'30" & $11^{\prime}$ \\
\hline
\end{tabular}

Tabel 2. Pengamatan Filtrat yang Dihasilkan

\begin{tabular}{llcc}
\hline \multirow{2}{*}{ No } & Metode Penyaringan & \multicolumn{2}{c}{ Filtrat } \\
\cline { 3 - 4 } & & Percobaan I & Percobaan II \\
\hline $\mathbf{1}$ & BVP & Jernih & Jernih \\
\hline
\end{tabular}




\begin{tabular}{llll}
\hline $\mathbf{2}$ & BVAK & Jernih & Jernih \\
\hline $\mathbf{3}$ & Penyaringan Sederhana & $\begin{array}{l}\text { tidak jernih } \\
\text { (agak keruh) }\end{array}$ & $\begin{array}{l}\text { tidak jernih } \\
\text { (agak keruh) }\end{array}$ \\
\hline
\end{tabular}

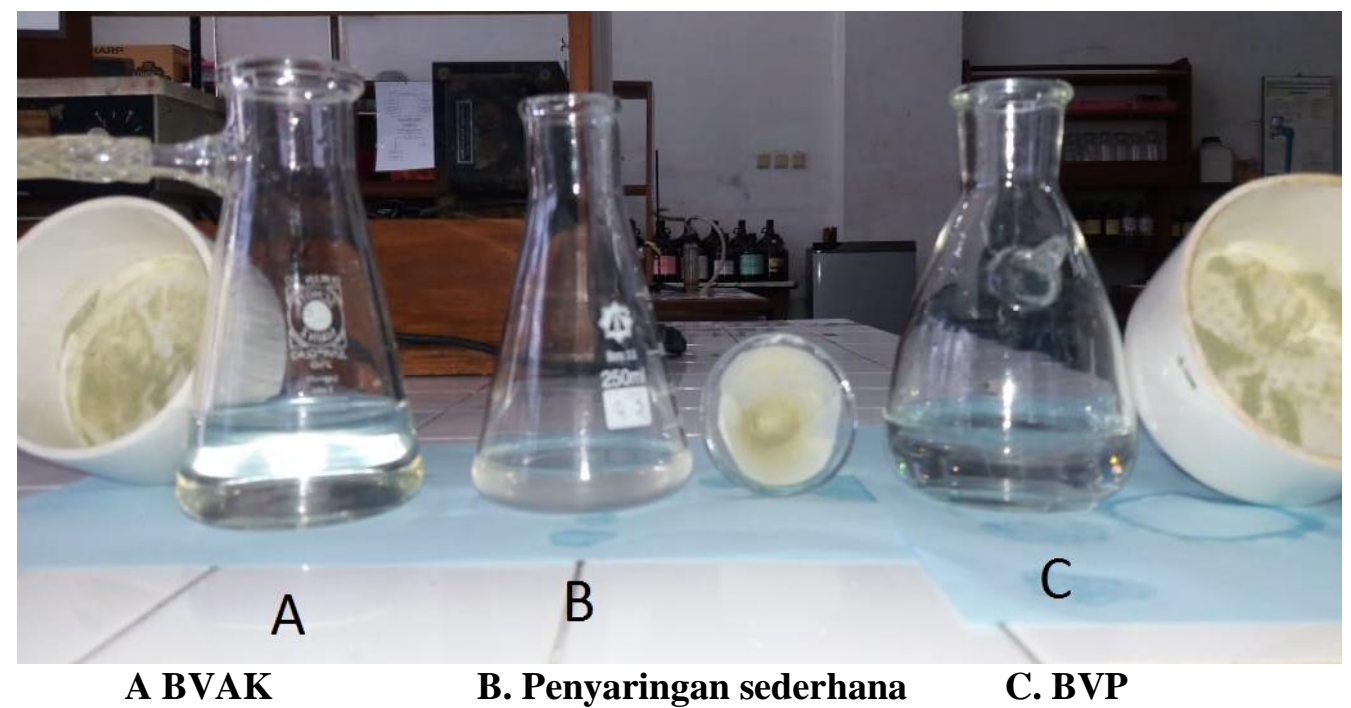

Gambar 4. Hasil Penyaringan (Filtrat)

Berdasarkan pengamatan terhadap lama proses penyaringan dari 3 (tiga) metode penyaringan, maka waktu penyaringan dengan metode BVP merupakan waktu tercepat 2,33-3 menit, yang ke dua BVAK 3,5-4,25 menit dan paling akhir adalah metode penyaringan sederhana 9,5-11 menit. Hal ini karena metode BVP dalam mengalirkan cairan untuk melalui septum/filter tidak hanya mengandalkan daya gravitasi seperti pada penyaringan dengan metode penyaringan sederhana. Tenaga dorong zat cair untuk melalui septum pada metode BVP dibantu oleh daya hisap pompa vakum sehingga laju cairan lebih cepat. Demikian pula halnya metode penyaringan BVAK adanya daya hisap vakum tenaga air kran menyebabkan cairan dalam suspensi terdorong lebih kuat melalui septum, walaupun kekuatan vakum air kran tidak sekuat dengan pompa (metode BVP) sehingga kecepatan proses lebih lambat. Kekuatan vakum air kran sangat bergantung kepada kekuatan aliran air.
Lamanya proses penyaringan pada penyaringan sederhana menyebabkan kondisi kertas saring lembab dalam waktu yang lebih lama sehingga kualitas penyaringan berkurang. Kemudian posisi kertas saring yang dibuat/ditekuk mengikuti bentuk corong mengarahkan arah penyaringan pada satu titik. Titik/bagian tengah kertas filter menjadi lemah untuk menahan partikel padat suspensi agar tetap bertahan. Tampaknya kedua hal tersebut yang menyebabkan kualitas filtrat hasil penyaringan sederhana tidak jernih atau kalah jernih dengan hasil filtrat metode BVP dan BVAK. Pada metode BVP dan BVAK pross terjadi secara cepat dan posisi penyaringan suspensi dapat dikatakan merata di semua permukaan kertas filter.

Berdasarkan lama waktu penyaringan dan hasil filtrat maka metode Buchner baik BVP maupun BVAK dapat digunakan sebagai alternatif proses penyaringan menggantikan penyaringan sederhana. Waktu proses yang lebih cepat dan filtrat yang lebih baik diharapkan dapat 
meningkatkan kualitas pelaksanaan praktikum. Pertimbangan penggunaan BVP atau BVAK tentunya didasarkan kepada ketersediaan alat dan kondisi. BVP memiliki kelebihan dalam kecepatan namun memerlukan energi listrik untuk menghidupkan pompa vakum. Untuk vakum tenaga aliran air maka harus dipertimbangkan banyaknya air kran/air bersih yang digunakan.

\section{KESIMPULAN}

Hasil penelitian menunjukan bahwa: 1. Waktu proses penyaringan tercepat adalah metode Buchner antara 2,33-3 menit dengan vakum pompa (BVP), kemudian Metode Buchner dengan vakum air kran (BVAK) 3,5-4,25 menit, dan proses terlama menggunakan penyaringan sederhana 9,5-11 menit; 2. Filtrat yang dihasilkan baik metode BVP ataupun BVAK tampak jernih, sedangkan filtrat dengan metode sederhana masih keruh.

Memperhatikan kecepatan waktu proses dan hasil filtrat maka BVP dan BVAK dapat digunakan sebagai alternatif proses penyaringan pada percobaan adsorbsi dalam praktikum kimia fisika.

\section{DAFTAR PUSTAKA}

Anonim, 2018, www.wikipedia.com.

Büchner_funnel: https://en.wikipedia.org/wiki/ Büchner_funnel.

Daniels, F. and Alberty, R.A., 1955, Physical Chemistry, John Willey and sons, Inc., New York, hal: 523-525.

Huisman, L, 1994, Rapid Sand Filtration, Lecture Notes, IHE Delft Netherlands.

Lynam, M.M., Kilduff, J.E., and Webber Jr., J., 1995, Journal of Chem. Ed. Vol. 72, hal: 81-82.

Moore, W.J., 1974, Physical Chemistry, edisi ke-4, Prentice-Hall, Inc., Indiana, hal: 517-518.

Reynolds, Tom D. dan Paul A. Richards, 1996, Unit and Processes and Environmental Enginering, PWS
Publishing Company, 20 Park plaza, MA 12116.

Rich, Linvil G., 1974, Unit Operations of sanitary Engineering, John Wiley \& Sons, Inc.

Roste, Ronald L., 1997, Theory and Practice of Water and Wasterwater Treatment, John Wiley \& Sons, Inc., 1997.

Staf Pendidik Laboratorium Kimia Fisika, 2017, Percobaan Kinetika Adsorpsi dan Percobaan Proses Isoterm Larutan, Buku Petunjuk Praktikum Kimia Fisika 1 dan 2. 